\title{
EFFECTS OF EXPOSURE TO ELECTROMAGNETIC FIELD RADIATION (EMFR) GENERATED BY ACTIVATED MOBILE PHONES ON FASTING BLOOD GLUCOSE
}

\author{
SULTAN AYOUB MEO ${ }^{1}$ and KHALID AL RUBEAAN ${ }^{2}$ \\ ${ }^{1}$ King Saud University, Riyadh, Saudi Arabia \\ Department of Physiology, College of Medicine \\ ${ }^{2}$ King Saud University, Riyadh, Saudi Arabia \\ University Diabetes Centre, College of Medicine
}

\begin{abstract}
Objective: Extensive use of mobile phones has been accompanied by a common public debate about possible adverse effects on human health. No study has been published so far to establish any association between the fastest growing innovation of mobile phone and fasting blood glucose. The aim was to determine the effects of exposure to electromagnetic field radiation generated by mobile phones on fasting blood glucose in Wistar Albino rats. Materials and Methods: 40 Male Albino rats (Wistar Strain) were divided into 5 equally numerous groups. Group A served as the control one, group B received mobile phone radiation for less than $15 \mathrm{~min} /$ day, group C: $15-30 \mathrm{~min} /$ day, group D: 31-45 min/day, and group E: 46-60 min/day for a total period of 3 months. Fasting blood glucose was determined by using Spectrophotometer and serum insulin by Enzyme-linked Immunosorbent Assay (ELISA). The Homeostatic Model (HOMA-B) was applied for the assessment of $\beta$-cell function and (HOMA-IR) for resistance to insulin. Results: Wister Albino rats exposed to mobile phone radiation for longer than $15 \mathrm{~min}$ a day for a total period of 3 months had significantly higher fasting blood glucose $(\mathrm{p}<0.015)$ and serum insulin $(p<0.01)$ compared to the control group. HOMA-IR for insulin resistance was significantly increased $(p<0.003)$ in the groups that were exposed for 15-30 and 46-60 min/day compared to the control rats. Conclusion: The results of the present study show an association between long-term exposure to activated mobile phones and increase in fasting blood glucose and serum insulin in Albino rats.
\end{abstract}

Key words:

Mobile phone radiation, Hyperglycemia, Insulin resistance, $\beta$-cell function

\section{INTRODUCTION}

The widespread use of mobile phones has been going skyhigh over the past decade and the applications offered by mobile phone technology have become an essential part of personal, business and social life [1], more recently they have also been used in telemedicine interventions [2-4]. The appearance changes and evolution of mobile phones have been one of the fastest in the history of innovation [5] and the number of mobile phone users worldwide has surpassed 4.8 billion, which means that every second a person on the planet uses a mobile phone [6].

Mobile phones are low-powered radio devices that transmit and receive radio frequency radiation at 900 $2000 \mathrm{MHz}[7,8]$. They are mainly placed in the front or side pockets of clothes or hung on a belt and held close to the skull while in use. In spite of the acknowledged

This work was supported by College of Medicine Research Center, Deanship of Scientific Research King Saud University, Riyadh.

Received: April 18, 2012. Accepted: April 25, 2013.

Corresponding author: S.A. Meo, Department of Physiology, College of Medicine, King Saud University, P.O. Box 2925. Riyadh 11461. Saudi Arabia (e-mail: sultanmeo@hotmail.com,smeo@ksu.edu.sa). 
benefits, mobile phone users often complain about burning sensations or a heating around the ear. The enhance in temperature may be due to the heating of a mobile phone, which is due to dissipation of electrical power and exposure to radio frequency (RF) [9]. Mobile phone users also report headaches, sleep disturbances, tension, fatigue, dizziness [1], impaired hearing and vision [10].

It has also been reported that exposure to mobile phones can cause detrimental effects to the central nervous system, cardiovascular and hematopoietic systems, as well as testis and utero-placental functions. It is also suspected of inducing cancer and possible effects on cellular DNA. Electromagnetic waves generated by mobile phones can inflict their results through both thermal and non-thermal effects [11]. Despite the large number of studies published over a decade, it still remains unclear whether the use of mobile phones may lead to serious debilitating problems such as mobile phone radiation-induced hyperglycemia. It is well acknowledged that sooner or later, if one develops hyperglycemia, it ultimately leads to diabetes mellitus.

Diabetes mellitus, is rapidly emerging as a global health care problem with devastating human, social and economic impact that threatens to reach pandemic levels by 2030 [12]. At present, approximately 250 million people worldwide live with diabetes and by 2025 this total is expected to increase to over 380 million. Furthermore, almost one million people a year and about 2 people a minute die due to the complications of diabetes mellitus [13]. It seems worthwhile to discuss the fact that for the last decade the use of mobile phones has skyrocketed and, similarly, the prevalence of diabetes mellitus has also been rising rather abruptly. No study has been published so far to establish any association between the world's fastest growing innovation, i.e. the mobile phone and rapidly emerging hyperglycemia / diabetes mellitus. Therefore, the aim of this study was to determine the effects of exposure to electromagnetic field radiation generated by mobile phones on fasting blood glucose in Wistar Albino rats.

\section{MATERIALS AND METHODS}

Animal Model: 40 male Albino rats (Wistar Strain), 2 months of age, weighing 150-160 g, with the same genetic background were used for the experiment. Animals were housed collectively ( 8 animals in each cage) and were fed with standard pellet diet (Gold Mohar) and water ad libitum. They were maintained under controlled temperature of $22-24^{\circ} \mathrm{C}$ and had a $12-12 \mathrm{~h}$ light-dark cycle (light on 6:00 a.m. - 6:00 p.m.) [14]. The animal experimental protocol was approved by the animal ethics board and the experiment was performed according to the suggested guidelines.

Experimental Protocol: All the animals were divided into five groups. Group A served as the control group, and the remaining four groups (B, C, D and E) were exposed to microwave radiation generated by a mobile phone at a specific time of the day (during the light period); group B: < 15, group C: $15-30$, group D: $31-45$ and group E: 46-60 min daily for a total period of 3 months. In this experiment, handsets of mobile phones of the same brand and model were used. A call was given from one set of a GSM (Global System for Mobile Communications) mobile phone to another set of a mobile phone, after ensuring that the mobile phone was powered-on and with the call accepting mode (answering mode) switched on, then the cell phone was placed inside the cage [14-17]. The cell phone was placed in the center of the cage to provide almost equal electromagnetic radiation to the whole body of the animals. The cage was made of plastic; the dimension of the cage was 18 inches in length and 12 inches in width. The animals were in a very close proximity to the cell phone. The electromagnetic field radiation generated by mobile phones was approximately $1800 \mathrm{MHz}$.

Fasting blood glucose and insulin analysis: At the end of the experimental period ( 3 months) the animals were kept fasting for $12 \mathrm{~h}$ and were anesthetized with Ether (Ethoxyethane), their blood was collected by cardiac puncture 
at (10-10:30 a.m.) to minimize the diurnal variation, and it was kept in plain container tubes, labeled with a specific code number. Blood samples were allowed to clot at room temperature and then centrifuged at $3000 \mathrm{rpm}$ for $10 \mathrm{~min}$; serum was separated and stored at $-70^{\circ} \mathrm{C}$ until the analysis. Fasting serum glucose was determined spectrophotometerically, with the use of the Dimension ${ }^{\circledR}$ Clinical Chemistry System, DADE Behring RXL-Max, USA and serum insulin was determined by Rat/Mouse Insulin Enzyme-linked Immunosorbent Assay (ELISA) Kit 96Well Plate (Cat-EZRMI 13 K), Linko Research, USA, and plates were read using Bio-Tek Instrument Inc, MicroPlate reader Model Elx-800, USA.

The Homeostasis Model Assessment (HOMA): For the determination of insulin resistance and the function of the pancreatic $\beta$-cells, the homeostasis model assessment (HOMA) provides valid and reliable information based on the fasting blood glucose levels and serum insulin [18]. This is the easiest and most popular assessment model for $\beta$-cell function derived from basal measurements of insulin and glucose [19]. The comparison of the fasting serum glucose values with the model's predictions allows a quantitative assessment of the contributions of insulin resistance and deficient $\beta$-cell function to the fasting hyperglycemia [20]. HOMA-B was calculated using the following formula: $20 \times$ fasting insulin / (fasting glucose -3.5 ) and HOMA-IR was computed as: fasting insulin $\times$ fasting glucose/22.5 [21].

Statistical analysis: Data were entered into the computer, and the SPSS version 13.0 was used. A Non-Parametric Kruskal-Wallis statistical test was used to find out the level of significance among the groups and Non-Parametric Mann-Whitney test was applied to compare the results between the control animals and the subjects exposed to radiation generated by mobile phones during different time periods. Data were expressed as median \pm interquartile range as well as mean \pm standard deviation (SD). P-value $<0.05$ was considered significant.

\section{RESULTS}

Table 1 shows the fasting serum glucose and serum insulin levels in Wistar Albino rats exposed to mobile phone radiation for $<15,15-30,31-45,46-60 \mathrm{~min} /$ day for the total period of 3 months as compared to the control group (Figures 1 and 2). Fasting blood glucose was significantly increased in the animals exposed to radiation for $15-30 \mathrm{~min} /$ day $(\mathrm{p}<0.01)$ and $46-60 \mathrm{~min} /$ day $(\mathrm{p}<0.03)$ compared to the controls. However, no significant difference in the fasting serum glucose was observed between the group exposed to mobile phone radiation for the period of less than $15 \mathrm{~min}$ and the group exposed for 31-45 min/day.

In group $\mathrm{D}$, the IQR and $\mathrm{SD}$ were high due to the higher value of FBS in one of the case, but there is no bimodal distribution. Furthermore, the fasting serum insulin level showed a significant increase in animals exposed to mobile phone radiation for the period of $31-45 \mathrm{~min} /$ day $(\mathrm{p}<0.01)$ and $45-60 \mathrm{~min} /$ day $(\mathrm{p}<0.03)$ as compared to the control group. Nevertheless, no significant difference in serum insulin was observed in animals exposed to mobile phone radiation for less than $15 \mathrm{~min} /$ day and $15-30 \mathrm{~min} /$ day for the period of three months.

Table 2 demonstrates the comparison of the $\beta$-cell function (HOMA-B) and serum insulin resistance (HOMA-IR)

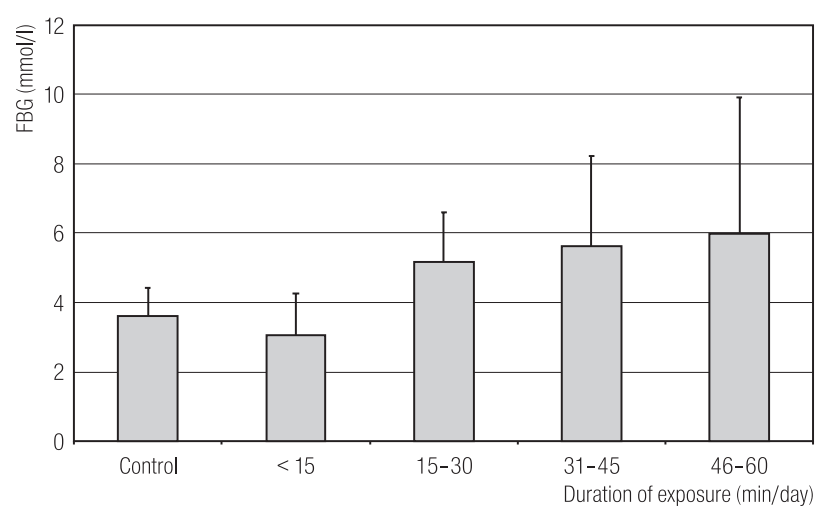

Fig. 1. Comparison of the effect of exposure duration to electromagnetic field radiation generated by activated mobile phones on the Fasting Blood Glucose (FBG) in Wistar Albino rats 
Table 1. Comparison of fasting blood glucose and serum insulin among Wistar Albino rats exposed to electromagnetic field radiation generated by an activated mobile phone compared to the control group

\begin{tabular}{lccccc}
\hline \multicolumn{1}{c}{ Parameter } & $\begin{array}{c}\text { Group A } \\
(\mathrm{N}=8)\end{array}$ & $\begin{array}{c}\text { Group B } \\
(\mathrm{N}=8)\end{array}$ & $\begin{array}{c}\text { Group C } \\
(\mathrm{N}=8)\end{array}$ & $\begin{array}{c}\text { Group D } \\
(\mathrm{N}=8)\end{array}$ & $\begin{array}{c}\text { Group E } \\
(\mathrm{N}=8)\end{array}$ \\
\hline FBG (mmol/lit) & & & & & \\
$\quad$ median (IQR) & $3.65(1.65)$ & $2.90(1.02)$ & $4.85(2.75)^{*}$ & $5.15(4.25)$ & $4.70(1.97)^{*}$ \\
M \pm SD & $3.62 \pm 0.79$ & $3.07 \pm 1.18$ & $5.17 \pm 1.41$ & $5.63 \pm 2.57$ & $5.98 \pm 3.93$ \\
Serum insulin (ng/ml) & & & & & \\
$\quad$ median (IQR) & $0.03(0.002)$ & $0.03(0.003)$ & $0.04(0.004)$ & $0.04(0.01)^{*}$ & $0.04(0.004)^{*}$ \\
M \pm SD & $0.0396 \pm 0.0016$ & $0.0398 \pm 0.0016$ & $0.0416 \pm 0.003$ & $0.0458 \pm 0.005$ & $0.0426 \pm 0.002$ \\
\hline
\end{tabular}

FBG - Fasting Blood Glucose; IQR - Interquartile Range.

$\mathrm{M}$ - mean; SD - standard deviation.

Group A - control. Exposed for the total period of 3 months: Group B - exposed for < 15 min/day; Group C - exposed for 15-30 min/day; Group D - exposed for 31-45 min/day; Group E - exposed for 46-60 min/day.

* Significant level among the groups from $\mathrm{p}<0.03$.



Fig. 2. Comparison of the effect of exposure duration to electromagnetic field radiation generated by activated mobile phones on serum insulin in Wistar Albino rats among the control subjects and the animals exposed to mobile phone radiation for $<15,15-30,31-45$ and 46-60 min/day for the total period of 3 months. A significant difference in the $\beta$-cell function (HOMA-B) was found between the control rats and the rats exposed to radiation for less than $15 \mathrm{~min} /$ day, but no significant difference for HOMA-B was observed in the other groups. Table 2 shows the comparison of serum insulin resistance (HOMA-IR) among the control rats and the animals exposed to mobile phone radiation throughout different time periods (Figure 3). There was significantly higher insulin resistance

Table 2. Comparison of the $\beta$-cell function (HOMA-B) and insulin resistance (HOMA-IR) among Wistar Albino rats exposed to electromagnetic field radiation generated by an activated mobile phone compared to the control group

\begin{tabular}{lccccc}
\hline \multicolumn{1}{c}{ Parameter } & $\begin{array}{c}\text { Group A } \\
(\mathrm{N}=8)\end{array}$ & $\begin{array}{c}\text { Group B } \\
(\mathrm{N}=8)\end{array}$ & $\begin{array}{c}\text { Group C } \\
(\mathrm{N}=8)\end{array}$ & $\begin{array}{c}\text { Group D } \\
(\mathrm{N}=8)\end{array}$ & $\begin{array}{c}\text { Group E } \\
(\mathrm{N}=8)\end{array}$ \\
\hline $\begin{array}{l}\text { HOMA-B } \\
\quad\end{array}$ & & & & & \\
$\quad$ median (IQR) & $0.7363(4.3325)$ & $-1.0750^{*}(1.8813)$ & $0.6216(1.7506)$ & $0.2444(2.0112)$ & $0.6714(0.6785)$ \\
$\mathrm{M} \pm \mathrm{SD}$ & $1.2553 \pm 3.1685$ & $-1.3713 \pm 1.3493$ & $1.2133 \pm 1.2878$ & $-1.2149 \pm 3.5374$ & $0.7889 \pm 0.6406$ \\
HOMA-IR & & & & & \\
$\quad$ median (IQR) & $0.00633(0.0032)$ & $0.0053(0.0018)$ & $0.00894 *(0.0048)$ & $0.00915(0.0120)$ & $0.00884^{*}(0.0047)$ \\
$\mathrm{M} \pm \mathrm{SD}$ & $0.00641 \pm 0.00157$ & $0.00547 \pm 0.00220$ & $0.00967 \pm 0.00325$ & $0.01190 \pm 0.00659$ & $0.01120 \pm 0.00686$ \\
\hline
\end{tabular}

HOMA-B - $\beta$-cell function; HOMA-IR - Insulin Resistance; IQR - Interquartile Range.

* Significant level among the groups A \& C, E from $p<0.003$.

Other abbreviations as in Table 1. 


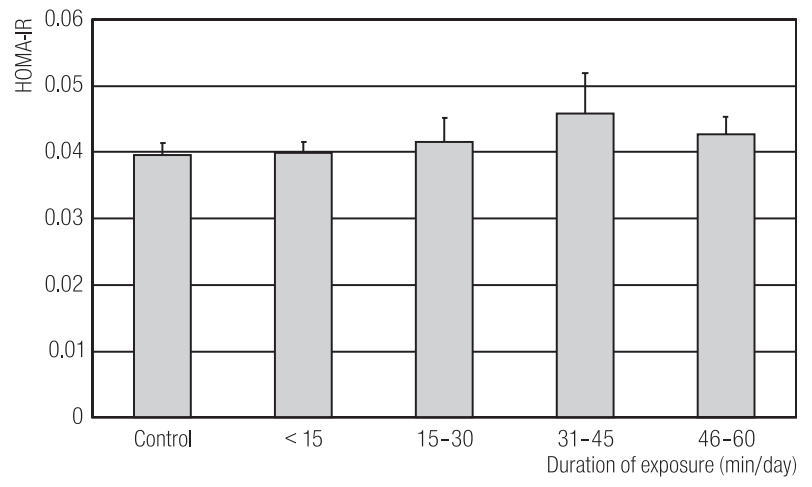

Fig. 3. Comparison of resistance to insulin based on HOMA-IR among Wistar Albino rats exposed to electromagnetic field radiation generated by activated mobile phones compared to the control group

among rats exposed to mobile phone radiation for 15-30 and 46-60 min/day for 3 months, but no significant differences in HOMA-IR was observed for the groups exposed to mobile phone radiation for $<15 \mathrm{~min}$ and $31-45 \mathrm{~min} /$ day.

\section{DISCUSSION}

Physiological functions are mainly based on the electrical events for keeping the body within the sufficient strength to perform the normal physiological functions. The possibility of induction of biological and health effects by low energy radiation emitted by mobile phones remains a debatable issue [22]. In spite of years of research, there is still an ongoing discussion whether such radiation could induce any physiologically relevant effects [22]. The vast majority of the research conducted so for has focused mainly on headaches, sleep disorders, or allergy-like symptoms [23] and cancer [24]. In addition, studies have also shown that mobile phone radiation has a wide range of damaging effects on the brain, heart, male reproductive system [11], eyes and it also causes oxidative damage [14], but no one has dealt yet with the emerging health problem such as mobile phone radiation-induced hyperglycemia. This is the first study in the literature which has shown a significant increase in fasting serum glucose levels in Albino rats that were exposed to mobile phone radiation for $15-30$ and $46-60 \mathrm{~min} / \mathrm{day}$ for the total period of three months. In addition, it manifested that the fasting serum insulin level increased significantly upon exposure to mobile phones for 31-45 and 46-60 min/day. It was also shown that HOMA-IR significantly increased in the groups which were exposed to the radiation in question for 15-30 and 46-60 $\mathrm{min} /$ day.

The findings of the present study support the concept that exposure to mobile phones throughout different time periods cause hyperglycemia with a simultaneous and significant increase in serum insulin levels. It is logical that hyperglycemia elicits insulin secretion. Eventually, a compensatory rise in the insulin level helps to control the hyperglycemia [25].

In the present study, we found that Wistar Albino rats exposed to mobile phones for less than 15 min showed no change in the blood glucose and serum insulin. It shows the usual relation between them, i.e. when blood glucose was low, insulin was also low. However, when the duration of exposure to mobile phone radiation was increased (15-30, 31-45 and 45-60 $\mathrm{min} /$ day for the total period of 3 months), blood glucose increased with a compensatory rise in the insulin level to control hyperglycemia.

It has been reported that sustained hyperglycemia induces early and severe $\beta$-cell dysfunction, and excess glucose causes $\beta$-cell loss via apoptosis [26]. Cell phone radiation can lead to the change of genetic regulation [27] and exacerbate oxidative stress $[14,28]$. Oxidative stress may more directly promote the onset of diabetes mellitus by decreasing insulin sensitivity and destroying the $\beta$-cell function within the pancreas [29]. It is well accredited that earlier or later if one develops hyperglycemia, it ultimately leads to the development of diabetes mellitus. Considering the results of the present study and its connection with mobile phone radiation, it is important to find out whether the resultant hyperglycemia is indeed associated with $\beta$-cell dysfunction or resistance to insulin. Diabetes mellitus is a metabolic disease that is characterized by hyperglycemia due to defects in 
insulin secretion, insulin action, or both insulin secretion and action. In fact, the reduced insulin secretion and its action frequently coexist and this abnormality becomes the prime cause of the increase in the blood glucose level [13]. In our study, hyperglycemia was hypothesized to be linked with increased insulin secretion. It was understood that hyperglycemia was not developed due to decreased secretion of insulin. Considering the association between hyperglycemia and increased insulin secretion, we applied Homeostasis Model Assessment (HOMA), which is based on the plasma levels of fasting glucose and insulin. This model has been widely applied for quantifying insulin resistance and $\beta$-cell function [18]. We found that HOMA-IR was significantly increased, and the increase in HOMA-IR reflects resistance to insulin [19].

\section{CONCLUSION}

The results of the present study show an association between long-term exposure to activated mobile phone and increases in fasting blood glucose and serum insulin. We cannot deny the benefits related to the services provided by the mobile phone industry, but we also strongly believe that health is more important and it cannot be compromised over anything. It is suggested that further studies may be conducted with added assessment and measurements of EMFR and FBG or insulin in a much larger group of animals, perhaps exposed for a much longer period than 3 months.

\section{ACKNOWLEDGEMENTS}

The authors are thankful to College of Medicine Research Center (CMRC) and the Deanship of Scientific Research, King Saud University, Riyadh, Saudi Arabia for supporting the research work. We would like to thank Prof. MA Azeem and Dr M Latifa for their critical review, and Dr M Shafi and Mr. Amir A Marzouk for data analysis.

\section{REFERENCES}

1. Al-Khalaiwi T, Meo SA. Association of mobile phone radiation with fatigue, headache, dizziness, tension and sleep disturbance in Saudi population. Saudi Med J 2004;25(6): 732-6.

2. Kim HS. A randomized controlled trial of a nurse shortmessage service by cellular phone for people with diabetes. Int J Nurs Stud 2007;44(5):687-92.

3. Kim HS, Jeong HS. A nurse short message service by cellular phone in type-2 diabetic patients for six months. J Clin Nurs 2007;16(6):1082-7.

4. Kim HS, Song MS. Technological intervention for obese patients with type 2 diabetes. Appl Nurs Res 2008;21(2):84-9.

5. Colonna A. Cellular phones and cancer: current status. Bull Cancer 2005;92(7):637-43.

6. Infobalt. More than four billion mobile phone users worldwide [cited 2011 Jan 24]. Available from URL: http://www.infobalt.lt/main.php?\&a=0\&i=7983.

7. Maier M, Colin B, Koivisto M. The health hazards of mobile phones. Br Med J 2000;320(2745)1288-9.

8. Kleinlogel H, Dierks T, Koenig T, Lehmann H, Minder A, Berz R. Effects of weak mobile phone-electromagnetic fields (GSM, UMTS) on well-being and resting EEG. Bioelectromagnetics 2008;29(6):479-87.

9. Straume A, Oftedal G, Johnsson A. Skin temperature increase caused by a mobile phone: A methodological infrared camera study. Bioelectromagnetics 2005;26(6):510-9.

10. Meo SA, Al Drees AM. Mobile phone related hazards and subjective hearing and vision symptoms in the Saudi Population. Int J Occup Med Environ Health 2005;18(1)53-7.

11. Derias EM, Stefanis P, Drakeley A, Gazvani R, LewisJones DI. Growing concern over the safety of using mobile phones and male fertility. Arch Androl 2006;52(1):9-14.

12. Hossain P, Kawar B, El Nahas M. Obesity and diabetes in the developing world: A growing challenge. N Engl J Med 2007;356(3):213-5.

13. American Diabetes Association: Diagnosis and classification of diabetes mellitus. Diabetes Care 2007;30:S42-7. 
14. Sokolovic D, Djindjic B, Nikolic J, Bjelakovic G, Pavlovic D, Kocic, $\mathrm{G}$ et al. Melatonin reduces oxidative stress induced by chronic exposure of microwave radiation from mobile phones in rat brain. J Radiat Res 2008;49(6):579-86.

15. Mailankot M, Kunnath AP, Jayalekshmi H, Koduru B, Valsalan R. Radio frequency electromagnetic radiation (RFEMR) from GSM (0.9/1.8 GHz) mobile phones induces oxidative stress and reduces sperm motility in rats. Clin Sao Paulo 2009;64(6):561-5.

16. Sareesh NN, Raju SK, Bhagath KP, Sheesha N, Maneesh M. Spatial Memory performance of Wistar rats exposed to mobile phone. Clinics 2009;64(3):231-4.

17. Gul A, Celebi H, Uğraş S. The effects of microwave emitted by cellular phones on ovarian follicles in rats. Arch Gynecol Obstet 2009;280(5):729-33.

18. Yiqing S, JoAnn EM, Lesley T, Barbara VH, Lewis H, Kuller LN, et al. Insulin sensitivity and insulin secretion determined by Homeostasis Model Assessment (HOMA) and risk of diabetes in a multiethnic cohort of women: The women's health initiative observational study. Diabetes Care 2007;30(7):1747-52.

19. Matthews DR, Hosker JP, Rudenski AS, Naylor BA, Treacher DF, Turner RC. Homeostasis Model Assessment: Insulin resistance and beta cell function from fasting plasma glucose and insulin concentrations in man. Diabetologia 1985;28(7): 412-9.

20. Turner RC, Rudenski AS, Matthews DR, Levy JC, O'Rahilly SP, Hosker JP. Application of structured model of glucose-insulin relations to assess B-cell function and insulin sensitivity. Horm Metab Res Suppl 1990;24:66-71.

21. Weng J, Li Y, Xu W, Shi L, Zhang Q, Zhu D. Effect of intensive insulin therapy on beta-cell function and glycaemic control in patients with newly diagnosed type 2 diabetes: A multicentre randomised parallel-group trial. Lancet 2008;371(9626): 1753-60.

22. Krewski D, Glickman BW, Habash RW, Habbick B, Lotz WG, Mandeville R, et al. Recent advances in research on radiofrequency fields and health: 2001-2003. J Toxicol Environ Health B Crit Rev 2007;10(4):287-318.

23. Seitz H, Stinner D, Eikmann T, Herr C, Röösli M. Electromagnetic hypersensitivity (EHS) and subjective health complaints associated with electromagnetic fields of mobile phone communication - A literature review published between 2000 and 2004. Sci Total Environ 2005;349(123):45-55.

24. French PW, Penny R, Laurence JA, McKenzie DR. Mobile phones, heat shock proteins and cancer. Differentiation 2001;67(4-5):93-7.

25. Kobayashi M. Effects of current therapeutic interventions on insulin resistance. Diabetes Obes Metab Suppl 1999;1: S32-401.

26. Zini E, Osto M, Franchini M, Guscetti F, Donath MY, Perren A, et al. Hyperglycaemia but not hyperlipidaemia causes beta cell dysfunction and beta cell loss in the domestic cat. Diabetologia 2009;52(2):336-46.

27. Balci M, Devrim E, Durak, I. Effects of mobile phones on oxidant/antioxidant balance in cornea and lens of rats. Curr Eye Res 2007;32(1):21-5.

28. Zhao TY, Zou SP, Knapp PE. Exposure to cell phone radiation up-regulates apoptosis genes in primary cultures of neurons and astrocytes. Neurosci Lett 2007;412(1):34-8.

29. Maiese K, Chong ZZ, Shang YS. Mechanistic insights into diabetes mellitus and oxidative stress. Curr Med Che 2007;14(16):1729-38.

This work is available in Open Access model and licensed under a Creative Commons Attribution-NonCommercial 3.0 Poland License - http://creativecommons.org/ licenses/by-nc/3.0/pl/deed.en. 